\title{
ARRANJO DE PLANTAS PARA DIFERENTES HÍBRIDOS DE MILHO ${ }^{1}$
}

\author{
Claudinei Kappes², João Antonio da Costa Andrade², Orivaldo $\operatorname{Arf}^{2}$, \\ Ângela Cristina de Oliveira², Marcelo Valentini Arf², João Paulo Ferreira ${ }^{2}$
}

\begin{abstract}
PLANTS SPATIAL ARRANGEMENT FOR DIFFERENT MAIZE HYBRIDS

Changes recently introduced to maize genotypes have made necessary to reassess the management practices recommendations for this culture, among them the plants spatial arrangement. This study was carried out to evaluate the best plant arrangement design for the maize hybrids XB 6010, XB 6012, XB 7253, XB 9003, and AG 9010, spaced at $0.45 \mathrm{~m}$ and $0.90 \mathrm{~m}$ among rows. The experiment was conducted on the 2009 harvest time, in Selvíria, Mato Grosso do Sul State, Brazil, with spacing arranged in strips and the combinations hybrids $\mathrm{x}$ populations arranged in a $5 \times 5$ factorial scheme for each block. The 50,000 plants ha ${ }^{-1}$; 60,000 plants ha ${ }^{-1} ; 70,000$ plants $\mathrm{ha}^{-1} ; 80,000$ plants ha ${ }^{-1}$; and 90,000 plants ha ${ }^{-1}$ populations were evaluated. The results were analyzed by using the F test, with the hybrids effects and row spacing compared by the Tukey test and populations compared by regression analysis. The hybrids differed in all features measured, what can be explained by intrinsic characteristics of each genotype. The increase of the population affected negatively most of the characters and yield components. Grain yield was influenced by the spatial arrangements, with different responses from hybrids. The best arrangements were AG $9010\left(90,000\right.$ plants ha- $\left.{ }^{-1}\right)$, for the $0.45 \mathrm{~m}$ row spacing; XB $7253\left(70,000\right.$ plants ha $\left.{ }^{-1}\right)$, for both row spacings; and XB 6010, XB 6012, and XB 9003, with no significant response to such arrangements, being recommended the 50,000 plants $\mathrm{ha}^{-1}$ one, for both row spacings.
\end{abstract}

KEY-WORDS: Zea mays L.; population density; plant arrangement; grain yield.

\section{INTRODUÇÃO}

O rendimento de grãos do milho é uma variável complexa e depende da interação entre fatores genéticos, ambientais e de manejo. No Brasil, o rendimento médio do milho é muito baixo, em decorrência de fatores ligados à fertilidade do solo, arranjo espacial de plantas (Fancelli \& Dourado Neto 2004),

\section{RESUMO}

Modificações introduzidas recentemente em genótipos de milho têm tornado necessário reavaliar as recomendações de práticas de manejo para esta cultura, dentre elas o arranjo espacial de plantas. Este trabalho foi realizado com o objetivo de verificar o melhor arranjo de plantas para os híbridos de milho XB 6010, XB 6012, XB 7253, XB 9003 e AG 9010, nos espaçamentos de $0,45 \mathrm{~m}$ e $0,90 \mathrm{~m}$ entre linhas. O experimento foi conduzido na safra 2009, em Selvíria (MS), com os espaçamentos dispostos em faixas e as combinações híbridos x populações em esquema fatorial $5 \times 5$, dentro de cada bloco. Foram avaliadas as populações de 50.000 plantas $\mathrm{ha}^{-1}$, 60.000 plantas ha ${ }^{-1}, 70.000$ plantas ha-1, 80.000 plantas $^{-1} \mathrm{ha}^{-1}$ 90.000 plantas $\mathrm{ha}^{-1}$. Os resultados foram submetidos ao teste $\mathrm{F}$, sendo os efeitos de híbridos e de espaçamentos comparados pelo teste Tukey e os de populações pela análise de regressão. Os híbridos se diferenciaram em todos os caracteres mensurados, atribuindo-se este fato às características intrínsecas de cada genótipo. $\mathrm{O}$ incremento da população influenciou negativamente a maioria dos caracteres e componentes de produção. $\mathrm{O}$ rendimento de grãos foi influenciado pelos arranjos espaciais, ocorrendo respostas diferenciadas dos híbridos. Os melhores arranjos foram AG 9010 (90.000 plantas ha-1), no espaçamento 0,45 m; XB 7253 (70.000 plantas ha-1), nos dois espaçamentos; e XB 6010, XB 6012 e XB 9003, sem resposta significativa aos arranjos, podendo ser recomendado o de 50.000 plantas ha $^{-1}$, nos dois espaçamentos.

PALAVRAS-CHAVE: Zea mays L.; densidade populacional; arranjo de plantas; rendimento de grãos.

uso de genótipos e práticas de manejo inadequadas (Sangoi et al. 2006).

A manipulação do arranjo espacial de plantas, pela alteração no espaçamento e na densidade de plantas na linha, tem sido apontada como uma das práticas de manejo mais importantes para maximizar o rendimento de grãos do milho, pela otimização do uso de fatores de produção como água, luz e

1. Trabalho recebido em abr./2010 e aceito para publicação em ago./2011 (n registro: PAT 9650/ DOI: 10.5216/pat.v41i3.9650).

2. Universidade Estadual Paulista, Faculdade de Engenharia de Ilha Solteira (FEIS/Unesp), Ilha Solteira, SP, Brasil.

E-mails: kappes.agro@gmail.com, arf@agr.feis.unesp.br, ferreirajpferreira@gmail.com, jandrade@bio.feis.unesp.br, angelagronomia2@hotmail.com,marceloarf@hotmail.com. 
nutrientes (Argenta et al. 2001a, Demétrio 2008). Recentemente, estudos objetivando a determinação do melhor arranjo espacial de plantas, nesta cultura, têm sido discutidos com maior frequência, em decorrência das variações morfológicas e genéticas apresentadas pelos híbridos atuais e do surgimento de novos genótipos e técnicas de manejo para a cultura, utilizando-se híbridos com elevado potencial produtivo.

Os híbridos modernos toleram maior densidade de plantas do que os híbridos antigos (Tollenaar 1992). Assim sendo, a tendência tem sido o estreitamento entre as linhas e o aumento da população de plantas. Argenta et al. (2001a), ao analisarem dois experimentos no Rio Grande do Sul, observaram clara evidência de que os incrementos no rendimento de grãos em linhas mais estreitas estavam mais associados a híbridos de ciclo superprecoce e baixa estatura.

A obtenção de novos híbridos gera a necessidade de avaliá-los em grande amplitude de condições edafoclimáticas (Cardoso et al. 2003) e demanda práticas de manejo mais adequadas para a maximização do seu potencial produtivo. Normalmente, a determinação do melhor arranjo de plantas é feita após a obtenção dos híbridos, que, por motivos de praticidade, ainda não foram submetidos a avaliações mais detalhadas, neste aspecto. Em contrapartida, informações para quantificar o efeito do aumento da população de plantas sobre a cultura são essenciais e, ao mesmo tempo, escassas, no Brasil. A despeito da carência de informações, alguns agricultores têm adotado, com sucesso, populações de até 72.000 plantas ha ${ }^{-1}$ e espaçamento de $0,40 \mathrm{~m}$ entre linhas (Fancelli \& Dourado Neto 2004).

Em virtude das modificações introduzidas nos genótipos de milho mais recentes, tais como menor estatura de planta e altura de inserção de espiga, menor esterilidade de plantas, menor duração do subperíodo de pendoamento-espigamento e plantas com folhas de angulação mais ereta e elevado potencial produtivo, torna-se necessário reavaliar as recomendações de práticas de manejo para esta cultura (Argenta et al. 2001a), como o arranjo de plantas.

Diante do exposto, propôs-se o presente estudo, com o objetivo de verificar o melhor arranjo de plantas, em dois espaçamentos entre linhas, para cinco híbridos de milho.

\section{MATERIAL E MÉTODOS}

O experimento foi conduzido em fazenda experimental, no município de Selvíria (MS) (20²0’ S, $51^{\circ} 24^{\prime} \mathrm{W}$ e $350 \mathrm{~m}$ de altitude). O clima da região, segundo classificação de Köppen, é do tipo Aw, com precipitação pluvial média anual de $1.330 \mathrm{~mm}$, temperatura média anual de $25^{\circ} \mathrm{C}$ e umidade relativa do ar média anual de 66\% (Centurion 1982). Os dados de precipitação pluvial e temperatura máxima e mínima do ar, por decêndio, foram coletados na Estação Metereológica da fazenda experimental (Figura 1).

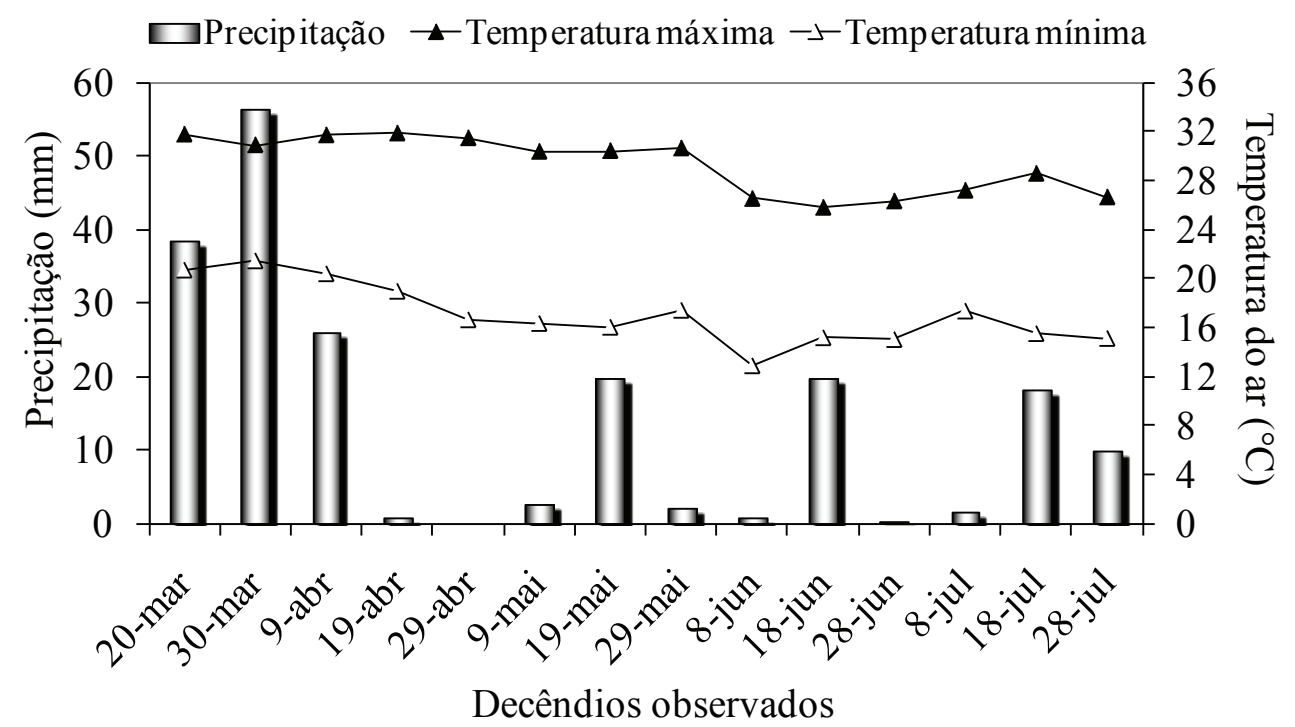

Figura 1. Precipitação pluvial e temperatura máxima e mínima do ar, por decêndio, registradas durante a condução do experimento (Selvíria, MS, 2009). 
O solo da área experimental é classificado como Latossolo Vermelho distrófico álico e de textura argilosa, de acordo com a denominação do Sistema Brasileiro de Classificação de Solos (Embrapa 2006), cuja análise química (camada $0-0,20 \mathrm{~m}$ ) revelou os seguintes valores: $\mathrm{MO}=28 \mathrm{~g} \mathrm{dm}^{-3} ; \mathrm{pH}\left(\mathrm{CaCl}_{2}\right)=5,4$; $\mathrm{P}($ resina $)=15 \mathrm{mg} \mathrm{dm}^{-3} ; \mathrm{S}=1 \mathrm{mg} \mathrm{dm}^{-3} ; \mathrm{B}=0,25 \mathrm{mg} \mathrm{dm}^{-3}$; $\mathrm{Cu}=2,9 \mathrm{mg} \mathrm{dm}^{-3} ; \mathrm{Fe}=22 \mathrm{mg} \mathrm{dm}^{-3} ; \mathrm{Mn}=26,6 \mathrm{mg} \mathrm{dm}^{-3}$; $\mathrm{Zn}=0,6 \mathrm{mgdm}^{-3} ; \mathrm{K}=3,4 \mathrm{mmol}_{\mathrm{c}} \mathrm{dm}^{-3} ; \mathrm{Ca}=24 \mathrm{mmol}_{\mathrm{c}} \mathrm{dm}^{-3}$; $\mathrm{Mg}=15 \mathrm{mmol}_{\mathrm{c}} \mathrm{dm}^{-3} ; \mathrm{H}+\mathrm{Al}=25 \mathrm{mmol}_{\mathrm{c}} \mathrm{dm}^{-3}$; $\mathrm{CTC}=67,4 \mathrm{mmol}_{\mathrm{c}} \mathrm{dm}^{-3}$; e V $=63 \%$.

Foram estabelecidos cinquenta tratamentos, com quatro repetições, resultantes da combinação dos fatores híbridos, espaçamentos e populações de plantas, e utilizados os seguintes híbridos de finalidade granífera, recomendados para o cultivo na região: XB 6010 (simples e superprecoce), XB 6012 (simples e precoce), XB 7253 (triplo e precoce), XB 9003 (simples e superprecoce) e AG 9010 (simples e superprecoce) $)^{1}$. Os espaçamentos foram de $0,45 \mathrm{~m}$ e $0,90 \mathrm{~m}$ entre linhas e as populações de 50.000 plantas ha-1, 60.000 plantas $\mathrm{ha}^{-1}, 70.000$ plantas ha-1, 80.000 plantas ha $^{-1} \mathrm{e} 90.000$ plantas ha $^{-1}$.

O delineamento experimental foi o de blocos casualizados, em esquema misto de faixas e fatorial. Os espaçamentos foram dispostos em faixas e as combinações híbridos x populações locadas em esquema fatorial $5 \times 5$, dentro de cada bloco e espaçamento. As parcelas foram constituídas por sete e quatro linhas de 4,5 $\mathrm{m}$ de comprimento, para os espaçamentos de $0,45 \mathrm{~m}$ e $0,90 \mathrm{~m}$ entre linhas, respectivamente, perfazendo área total de $14,2 \mathrm{~m}^{2}$ e $16,2 \mathrm{~m}^{2}$, respectivamente. Para coleta dos dados, foram utilizadas somente as quatro e as duas linhas centrais, nos espaçamentos de $0,45 \mathrm{~m}$ e $0,90 \mathrm{~m}$ entre linhas, respectivamente. Assim, a área útil experimental foi de $8,1 \mathrm{~m}^{2}$, em ambos os espaçamentos utilizados.

O experimento foi instalado em área cultivada com sistema plantio direto há mais de cinco anos, a qual foi ocupada com feijão, no período de inverno do ano agrícola de 2008, permanecendo em pousio no verão seguinte. Na semana que antecedeu a semeadura, as plantas daninhas presentes na área, na qual predominavam a trapoeraba [Commelina benghalensis (L.)] e a nabiça [Raphanus raphanistrum (L.)], foram dessecadas com glyphosate ( $1.920 \mathrm{~g} \mathrm{ha}^{-1}$ do i.a.). As sementes foram tratadas com inseticida tiodicarbe

\footnotetext{
Nomes de produtos comerciais e sua utilização no experimento não caracterizam recomendação ou preferência dos autores.
}

(1.050 g do i.a./100 kg de sementes) e a semeadura realizada no dia 20 de março de 2009 , de forma manual, com a utilização de matracas, sendo as covas espaçadas de forma equidistante, de acordo com a população almejada e o espaçamento utilizado. Foi semeado o dobro da quantidade de sementes, sendo realizado o desbaste quando as plantas estavam com sete folhas completamente desdobradas, deixando-se uma planta por cova, objetivando-se ajustar as populações almejadas. Cinco dias após a semeadura, a área foi irrigada por aspersão (sistema do tipo pivô central), com uma lâmina de água de, aproximadamente, $13 \mathrm{~mm}$, para promover a germinação e emergência uniforme das plântulas.

A adubação mineral foi realizada com base nas características químicas do solo e nas recomendações propostas por Raij et al. (1996), com rendimento esperado de $8 \mathrm{t} \mathrm{ha}^{-1}$. Foram aplicados $260 \mathrm{~kg} \mathrm{ha}^{-1} \mathrm{da}$ fórmula $08-28-16$ ( + 1\% de Ca, $2 \%$ de $\mathrm{S}$ e $0,3 \%$ de $\mathrm{Zn)}$. A abertura dos sulcos e a distribuição do fertilizante foram realizadas com semeadora específica para o sistema plantio direto, com mecanismo sulcador de hastes. A adubação de cobertura foi realizada quando $50 \%$ das plantas apresentavam seis folhas completamente desdobradas, aplicando-se $110 \mathrm{~kg} \mathrm{ha}^{-1}$ de $\mathrm{N}$, na forma de ureia $(45 \%$ de $\mathrm{N})$. A aplicação do fertilizante ocorreu de forma mecanizada, em cobertura superficial à lanço (sem incorporação), seguida de irrigação por aspersão (lâmina de, aproximadamente, $13 \mathrm{~mm}$ ), para minimizar as perdas de $\mathrm{N}$ por volatilização da amônia, conforme ressaltado por Costa et al. (2004). O fornecimento de água, nos períodos de estiagem, foi realizado por aspersão, com uma lâmina de água de, aproximadamente, $13 \mathrm{~mm}$ e turno de irrigação de três dias.

As plantas daninhas foram controladas em pós-emergência, utilizando-se os herbicidas atrazina e tembotriona $\left(1.000+84 \mathrm{~g} \mathrm{ha}^{-1}\right.$ do i.a., respectivamente), em forma de mistura. Adicionou-se à calda de aplicação o adjuvante éster metilado de óleo de soja (720 $\mathrm{g} \mathrm{ha}^{-1}$ do i.a.). No momento da aplicação, as plantas daninhas estavam nos estádios inicias de desenvolvimento e a cultura encontrava-se com $50 \%$ das plantas com cinco folhas completamente desdobradas. Para o controle da lagarta do cartucho [Spodoptera frugiperda (J.E. Smith)], foi suficiente uma aplicação de zetacypermethrin $\left(20 \mathrm{~g} \mathrm{ha}^{-1}\right.$ do i.a.). As aplicações dos produtos fitossanitários foram realizadas mediante o uso de pulverizador de barras tratorizado, regulado para aplicar $220 \mathrm{~L} \mathrm{ha}^{-1}$ de calda. 
Foram mensurados os seguintes caracteres: a) florescimento feminino: número de dias contabilizados a partir da semeadura, para que $50 \%$ das plantas apresentassem estilo-estigmas emitidos com, no mínimo, $3 \mathrm{~cm}$ de comprimento; b) acamamento de planta: percentual de plantas com colmo formando ângulo maior que $20^{\circ} \mathrm{com}$ a vertical, por ocasião da colheita; c) quebramento de planta: percentual de plantas com o colmo quebrado abaixo da inserção da espiga principal, por ocasião da colheita; d) diâmetro de sabugo: considerado o ponto central do sabugo; e) comprimento de grão: obtido pela diferença entre o diâmetro de espiga e o diâmetro de sabugo, conforme metodologia utilizada por Kappes et al. (2009); f) número de fileiras de grãos por espiga. Na determinação do diâmetro de sabugo, comprimento de grão e número de fileiras de grãos por espiga, foram utilizadas dez espigas tomadas ao acaso, em cada parcela.

A colheita foi realizada no dia 28 de julho de 2009, correspondendo a 130 dias após a semeadura. O rendimento de grãos foi obtido a partir da debulha e pesagem dos grãos oriundos de todas as espigas colhidas na área útil das parcelas, sendo convertido para $\mathrm{kg} \mathrm{ha}^{-1}$ e corrigido para $130 \mathrm{~g} \mathrm{~kg}^{-1}$ de teor de água (base úmida).

$\mathrm{Na}$ análise estatística de acamamento e quebramento de planta, os resultados foram transformados em $\sqrt{ } \mathrm{x}+0,5$, para atender aos pressupostos básicos da análise de variância (ANOVA). Em seguida, os resultados foram submetidos ao teste $\mathrm{F}$ da análise de variância, sendo os efeitos de híbridos e de espaçamentos comparados pelo teste Tukey (5\%), de acordo com Gomes \& Garcia (2002). O efeito de populações de plantas foi avaliado por meio de análise de regressão polinomial, considerando-se apenas as equações significativas pelo teste $\mathrm{F}(\mathrm{p}<0,05)$. Utilizou-se o software SAS, para as análises.

\section{RESULTADOS E DISCUSSÃO}

Os dados de temperatura do ar (Figura 1), fator que intervém em quase todas as funções da planta, indicam que, durante a condução do experimento, a mesma foi adequada para o desenvolvimento da cultura, haja vista que o milho produz melhor sob temperaturas moderadas (Didonet et al. 2002) e que a variação constatada foi entre $12,9^{\circ} \mathrm{C}$ e $31,8^{\circ} \mathrm{C}$. Por outro lado, a precipitação pluvial total constatada durante o período experimental $(158 \mathrm{~mm})$ foi considerada inadequada para o bom desenvolvimento da cultura, uma vez que a literatura tem indicado exigência média entre $350 \mathrm{~mm}$ e $500 \mathrm{~mm}$ de precipitação, para que produza satisfatoriamente, sem a necessidade de irrigação. Além disto, a ocorrência de três veranicos (primeiro: final da fase vegetativa; segundo: final do período de florescimento e início do enchimento de grãos; e terceiro: nos $50 \%$ finais da fase de enchimento de grãos) justificou a utilização da irrigação suplementar, especialmente no enchimento de grãos.

O espaçamento não influenciou o número de dias para o florescimento feminino das plantas (Tabela 1). Por outro lado, foi constatada interação significativa entre híbridos e população de plantas. No desdobramento (Tabela 2), houve diferença significativa entre os híbridos, dentro de todas as populações, sendo que, em 50.000 plantas ha ${ }^{-1}$ e 80.000 plantas ha $^{-1}$ e em 70.000 plantas ha $^{-1}$ e 90.000 plantas ha $^{-1}$, os híbridos se comportaram de maneira similar. O híbrido AG 9010 foi o que necessitou de menos dias para que $50 \%$ das plantas alcançassem o florescimento feminino, em todas as populações, evidenciando sua característica de superprecocidade relatada pela empresa produtora das sementes. Por outro lado, o híbrido XB 6012 necessitou de maior número de dias para as plantas atingirem o florescimento feminino, nas populações de 60.000 plantas ha-1, 70.000 plantas ha- e 90.000 plantas ha ${ }^{-1}$. Os híbridos XB 6010 e XB 9003 tiveram comportamento similar, sob todas as populações de plantas, e não se diferenciaram significativamente.

$\mathrm{Na}$ análise de regressão, com exceção do AG 9010, todos os híbridos responderam de forma linear positiva ao aumento da população (Figura 2a), demonstrando que o incremento na densidade de plantas proporciona maior duração da fase vegetativa da cultura. Neste caso, pode-se inferir que, em função de sua arquitetura diferenciada, o AG 9010 permite um maior adensamento de plantas, sem interferência nos processos fisiológicos envolvidos no florescimento.

$\mathrm{O}$ acamamento e quebramento de planta apresentaram comportamento semelhante neste estudo, ao não serem afetados pela alteração no espaçamento, mas apenas pelos híbridos e populações de plantas, de forma independente (Tabela 1). O híbrido XB 9003 apresentou baixo percentual de acamamento de planta e não se diferenciou dos genótipos XB 6010, XB 7253 e AG 9010. Fica evidente que a ocorrência de acamamento, com o aumento da densidade populacional, é dependente do genótipo. Kunz (2005) 
Tabela 1. Valores médios de florescimento feminino (FF), acamamento de planta (AC), quebramento de planta (QB), diâmetro de sabugo (DS), comprimento de grão (CG), número de fileiras de grãos por espiga (FG) e rendimento de grãos (RG), em função de arranjos espaciais de plantas, na cultura do milho (Selvíria, MS, 2009).

\begin{tabular}{|c|c|c|c|c|c|c|c|c|}
\hline \multirow[b]{2}{*}{ Tratamentos } & & $\mathrm{FF}$ & $\mathrm{AC}^{(1)}$ & $\mathrm{QB}^{(1)}$ & DS & $\mathrm{CG}$ & FG & RG \\
\hline & & dias & \multicolumn{2}{|c|}{$\%$} & \multicolumn{2}{|c|}{$\mathrm{mm}-$} & $\mathrm{n}^{\mathrm{o}}$ & $\mathrm{kg} \mathrm{ha}^{-1}$ \\
\hline \multicolumn{9}{|l|}{ Híbrido $(\mathrm{H})$} \\
\hline \multicolumn{2}{|l|}{ XB 6010} & 56,7 & $0,73 \mathrm{ab}$ & $1,06 \mathrm{ab}$ & $29,4 \mathrm{a}$ & 9,7 & 13,3 & 6.788 \\
\hline \multicolumn{2}{|l|}{ XB 6012} & 62,1 & $0,87 \mathrm{a}$ & $0,86 \mathrm{~b}$ & $28,7 \quad b$ & 10,3 & 13,7 & 6.974 \\
\hline \multicolumn{2}{|l|}{ XB 7253} & 59,9 & $0,81 \mathrm{ab}$ & $1,32 \mathrm{a}$ & $28,4 \mathrm{~b}$ & 9,8 & 13,1 & 7.664 \\
\hline \multicolumn{2}{|l|}{ XB 9003} & 56,8 & $0,71 \mathrm{~b}$ & $0,88 \mathrm{~b}$ & $29,2 \mathrm{a}$ & 9,6 & 12,9 & 7.319 \\
\hline \multicolumn{2}{|l|}{ AG 9010} & 49,0 & $0,73 \mathrm{ab}$ & $0,84 \mathrm{~b}$ & $28,4 \quad b$ & 8,6 & 13,8 & 6.093 \\
\hline \multicolumn{2}{|l|}{ DMS (5\%) } & 0,72 & 0,15 & 0,33 & 0,38 & 0,32 & 0,27 & 367,73 \\
\hline \multicolumn{2}{|c|}{ Teste F } & $750,37 * *$ & $3,59 *$ & $4,92 * *$ & $20,67 * *$ & $57,21 * *$ & $29,22 * *$ & $40,65 * *$ \\
\hline \multicolumn{9}{|c|}{ Espaçamento (E) } \\
\hline \multirow{2}{*}{\multicolumn{2}{|c|}{$0,45 \mathrm{~m}$}} & 56,7 & 0,75 & 0,99 & 28,9 & 9,6 & 13,4 & 7.121 \\
\hline \multirow{2}{*}{\multicolumn{2}{|c|}{$\begin{array}{l}0,90 \mathrm{~m} \\
\text { DMS (5\%) }\end{array}$}} & 57,1 & 0,79 & 1,04 & 28,8 & 9,6 & 13,3 & 6.814 \\
\hline & & 0,61 & 0,08 & 0,15 & 0,27 & 0,21 & 0,21 & 418,15 \\
\hline \multicolumn{2}{|l|}{ Teste F } & 3,94 & 2,31 & 1,10 & 3,01 & 0,46 & 1,24 & 5,44 \\
\hline \multicolumn{9}{|c|}{ População (P) } \\
\hline & 56,1 & 0,71 & 0,99 & 29,5 & 9,8 & 13,4 & 6.584 \\
\hline \multicolumn{2}{|c|}{$\begin{array}{l}50.000 \text { plantas } \mathrm{ha}^{-1} \\
60.000 \text { plantas ha }\end{array}$} & 56,7 & 0,75 & 0,86 & 29,3 & 9,7 & 13,6 & 6.804 \\
\hline & 56,7 & 0,74 & 0,94 & 28,7 & 9,4 & 13,3 & 7.113 \\
\hline \multicolumn{2}{|c|}{80.000 plantas ha $^{-1}$} & 57,9 & 0,78 & 1,04 & 28,4 & 9,5 & 13,3 & 7.225 \\
\hline \multicolumn{2}{|c|}{90.000 plantas ha-1 } & 57,6 & 0,87 & 1,26 & 28,2 & 9,4 & 13,2 & 7.110 \\
\hline \multicolumn{2}{|c|}{ Teste F } & $9,96 * *$ & $2,73 *$ & $3,31 *$ & $34,98 * *$ & $4,69 * *$ & $3,77 * *$ & $8,15^{* *}$ \\
\hline \multirow{4}{*}{$\begin{array}{l}\text { Teste F } \\
\text { (interação) }\end{array}$} & $\mathrm{H} \times \mathrm{E}$ & 2,16 & 1,34 & 0,19 & 0,66 & 0,70 & 1,45 & $4,50 * *$ \\
\hline & $\mathrm{H} \times \mathrm{P}$ & $1,86^{*}$ & 1,41 & 0,76 & 0,92 & $1,87^{*}$ & $1,99 *$ & $2,50 * *$ \\
\hline & Ex P & 1,55 & 1,50 & 0,47 & 0,78 & 0,58 & 0,67 & 1,39 \\
\hline & $\mathrm{H} \times \mathrm{E} \times \mathrm{P}$ & 0,63 & 0,92 & 0,50 & 0,48 & 0,40 & 1,02 & 1,29 \\
\hline \multirow{2}{*}{\multicolumn{2}{|c|}{$\begin{array}{l}\text { Média geral } \\
\text { CV (\%) }\end{array}$}} & 56,9 & 0,77 & 1,02 & 28,9 & 9,6 & 13,4 & 6.967 \\
\hline & & 1,76 & 32,67 & 42,05 & 2,43 & 6,76 & 3,12 & 8,84 \\
\hline
\end{tabular}

** e * Significativo a $1 \%$ e $5 \%$, pelo teste F, respectivamente. Médias seguidas por letras distintas diferem pelo teste Tukey (5\%). DMS: diferença mínima significativa, pelo teste Tukey. CV: coeficiente de variação. ${ }^{(1)}$ Resultados transformados em $\sqrt{ } \mathrm{x}+0,5$.

Tabela 2. Desdobramento da interação entre híbrido e população de plantas, para florescimento feminino (dias), na cultura do milho (Selvíria, MS, 2009).

\begin{tabular}{cccccc}
\hline \multirow{2}{*}{ Híbrido } & \multicolumn{5}{c}{ Florescimento feminino (dias) $^{-1}$} \\
\cline { 2 - 5 } & 50.000 plantas ha $^{-1}$ & 60.000 plantas ha $^{-1}$ & 70.000 plantas ha $^{-1}$ & 80.000 plantas ha $^{-1}$ & 90.000 plantas ha $^{-1}$ \\
XB 6010 & $54,9 \mathrm{~b}$ & $57,5 \mathrm{bc}$ & $56,1 \mathrm{c}$ & $57,4 \mathrm{~b}$ & $57,7 \mathrm{c}$ \\
XB 6012 & $61,1 \mathrm{a}$ & $61,9 \mathrm{a}$ & $62,4 \mathrm{a}$ & $62,2 \mathrm{a}$ & $63,0 \mathrm{a}$ \\
XB 7253 & $59,2 \mathrm{a}$ & $59,6 \mathrm{~b}$ & $60,1 \mathrm{~b}$ & $60,2 \mathrm{a}$ & $60,5 \mathrm{~b}$ \\
XB 9003 & $56,2 \mathrm{~b}$ & $55,7 \mathrm{c}$ & $56,7 \mathrm{c}$ & $57,4 \mathrm{~b}$ & $57,7 \mathrm{c}$ \\
AG 9010 & $49,0 \mathrm{c}$ & $49,0 \mathrm{~d}$ & $49,0 \mathrm{~d}$ & $49,0 \mathrm{c}$ & $49,1 \mathrm{~d}$ \\
\hline
\end{tabular}

Médias seguidas por mesma letra, nas colunas, não diferem pelo teste Tukey (5\%).

observou aumento do acamamento em dois dos quatro híbridos de milho avaliados. Esta diferença entre híbridos é justificada pelo autor devido ao fato de alguns híbridos serem naturalmente susceptíveis ao acamamento em altas populações, ao aumento de doenças de colmo e à redução do sistema radicular.

O percentual de plantas acamadas aumentou linearmente com o incremento da população de plantas (Figura 2b), discordando dos dados apresentados por Sangoi et al. (2002), que não observaram variação na porcentagem de plantas acamadas, com o aumento de 25.000 plantas ha $^{-1}$ para 100.000 plantas ha ${ }^{-1}$, em três híbridos de milho. O fato aqui evidenciado é justificado pela maior competição intraespecífica pelos recursos do ambiente (Argenta et al. 2001b), prejudicando a manutenção das demais estruturas do vegetal, notadamente sobre o diâmetro de colmo.

Apesar de não terem sido mensuradas neste estudo, outra hipótese pode estar relacionada à quantidade de raiz e de parte aérea de plantas, nas diferentes populações, pois, na pesquisa de Dourado Neto et al. (2003), a quantidade relativa de raiz, no período de florescimento, em relação à massa de matéria seca total, diminuiu de $26 \%$ para $19 \%$, com o aumento 
de 30.000 plantas ha-1 para 90.000 plantas ha $^{-1}$. Já a parte aérea aumentou de $74 \%$ para $81 \%$, explicando, parcialmente, porque populações elevadas apresentaram maior percentagem de acamamento e quebramento de planta.

No tocante ao quebramento de planta (Tabela 1), menores percentuais foram detectados nos híbridos XB 6012, XB 9003, AG 9010 e XB 6010. De modo geral, o híbrido AG 9010 apresentou baixos percentuais, tanto de acamamento quanto de quebramento de planta, fato explicado pelas suas características de genótipo moderno, como ciclo superprecoce, arquitetura foliar ereta, baixa altura de planta e de inserção de espiga, excelente "stay green" e menor área foliar. Porém, os híbridos XB 6010, XB 7253 e XB 9003 também apresentaram baixo percentual de acamamento, apesar de possuírem características agronômicas diferenciadas, com relação ao AG 9010, como arquitetura foliar semiereta, maior altura de planta e de inserção de espiga. Isto demonstra que, de fato, estas características não se constituíram em

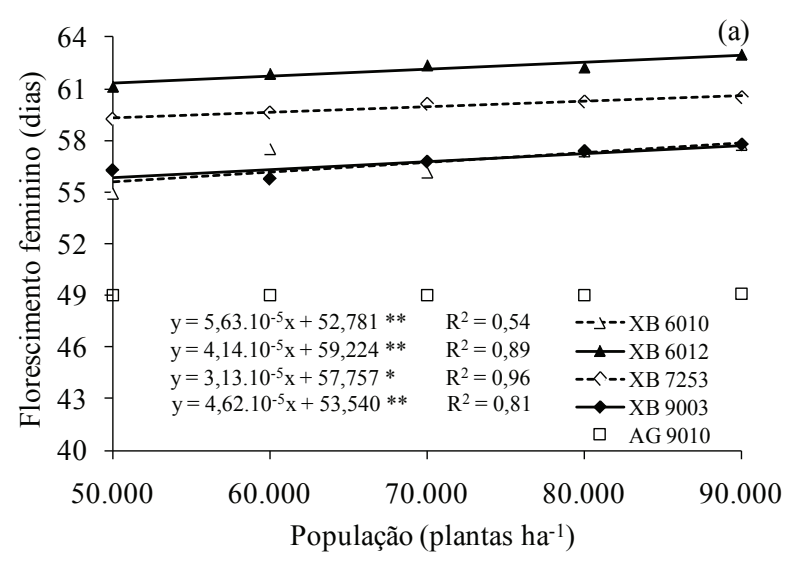

(b)

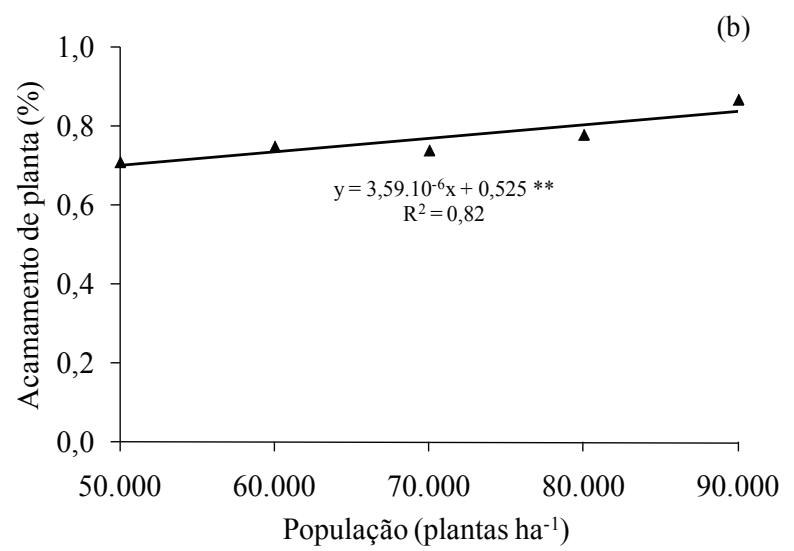

fatores limitantes ao incremento na população de plantas, até 90.000 plantas ha $^{-1}$, e no rendimento de grãos, sob as condições em que se conduziu este trabalho.

Assim como foi verificado para o acamamento, o percentual de plantas quebradas aumentou linearmente à medida que se incrementou a densidade populacional (Figura 2c). $\mathrm{O}$ aumento do acamamento e quebramento de planta, com o incremento da população, também foi relatado por outros pesquisadores (Sangoi et al. 2002, Furtado 2005, Gross et al. 2006, Brachtvogel 2008). Por outro lado, contraria os resultados de Bruns \& Abbas (2005), Carvalho (2007) e Demétrio (2008), que não observaram influência da alteração na população de plantas sobre estas características agronômicas.

O diâmetro de sabugo não foi afetado pela alteração no espaçamento e pela interação entre os fatores considerados (Tabela 1). Houve apenas efeito significativo e independente de híbrido e população de plantas, constatando-se que espigas dos híbridos XB 6010 e XB 9003 apresentaram maior diâmetro de sabugo. Marchão et al. (2005) conduziram dois experimentos, avaliando características agronômicas de híbridos de milho (A 2555, A 2288, AG 9010, AG 6690, P 30F88 e Valent), em diferentes populações (40.000 plantas ha-1, 55.000 plantas ha ${ }^{-1}, 70.000$ plantas ha- ${ }^{-1}, 85.000$ plantas ha $^{-1}$ e 100.000 plantas ha $^{-1}$ ), sob espaçamento de $0,45 \mathrm{~m}$ entre linhas, e também não obtiveram interação entre os fatores estudados, em ambos os experimentos. Perante análise de regressão, observa-se que o incremento na população de plantas provocou redução linear do diâmetro de sabugo (Figura 3a), corroborando vários traba-

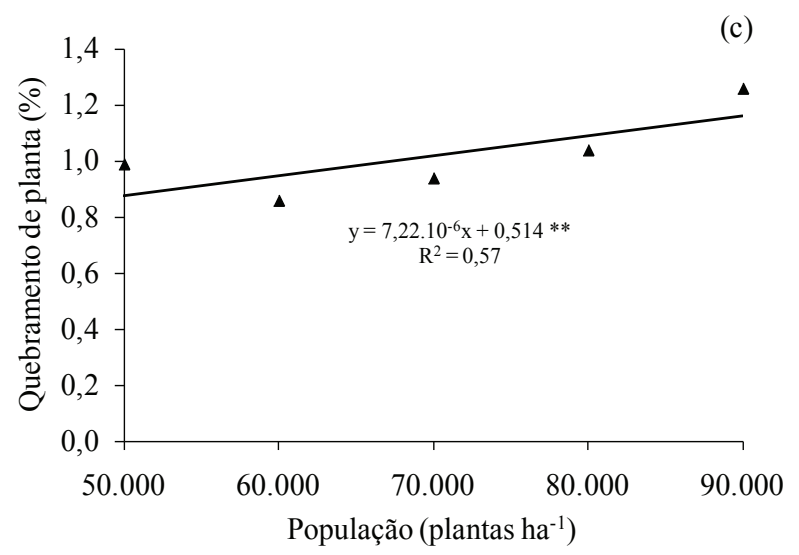

Figura 2. Florescimento feminino (a), acamamento de planta (b) e quebramento de planta de milho (c), em função de populações de plantas (Selvíria, MS, 2009). ** e* Significativo a $1 \%$ e $5 \%$, respectivamente, pelo teste $\mathrm{F}$. 
lhos de pesquisa, dentre eles os desenvolvidos por Brachtvogel et al. (2009) e Marchão et al. (2005). Novamente, fica evidenciado que o aumento do número de plantas por unidade de área promove maior competição intraespecífica pelos recursos do ambiente (Argenta et al. 2001b), prejudicando a manutenção das demais estruturas do vegetal, dentre elas o desenvolvimento da espiga.

O comprimento de grão foi influenciado pelo híbrido, população e pela interação entre estes fatores (Tabela 1). No comportamento dos híbridos, dentro das respectivas populações, por meio do desdobramento (Tabela 3), os híbridos XB 6010, XB 6012, XB 7253 e XB 9003 se comportaram de modo similar, sob 50.000 plantas ha ${ }^{-1}, 60.000$ plantas ha-1, 80.000 plantas ha $^{-1}$ e 90.000 plantas ha $^{-1}$, apresentando grãos mais compridos, em relação ao AG 9010. Na população de 70.000 plantas ha $^{-1}$, o híbrido XB 9003 não manteve sua superioridade e não se diferenciou do AG 9010, apresentando, portanto, grãos mais curtos, em relação aos demais genótipos.
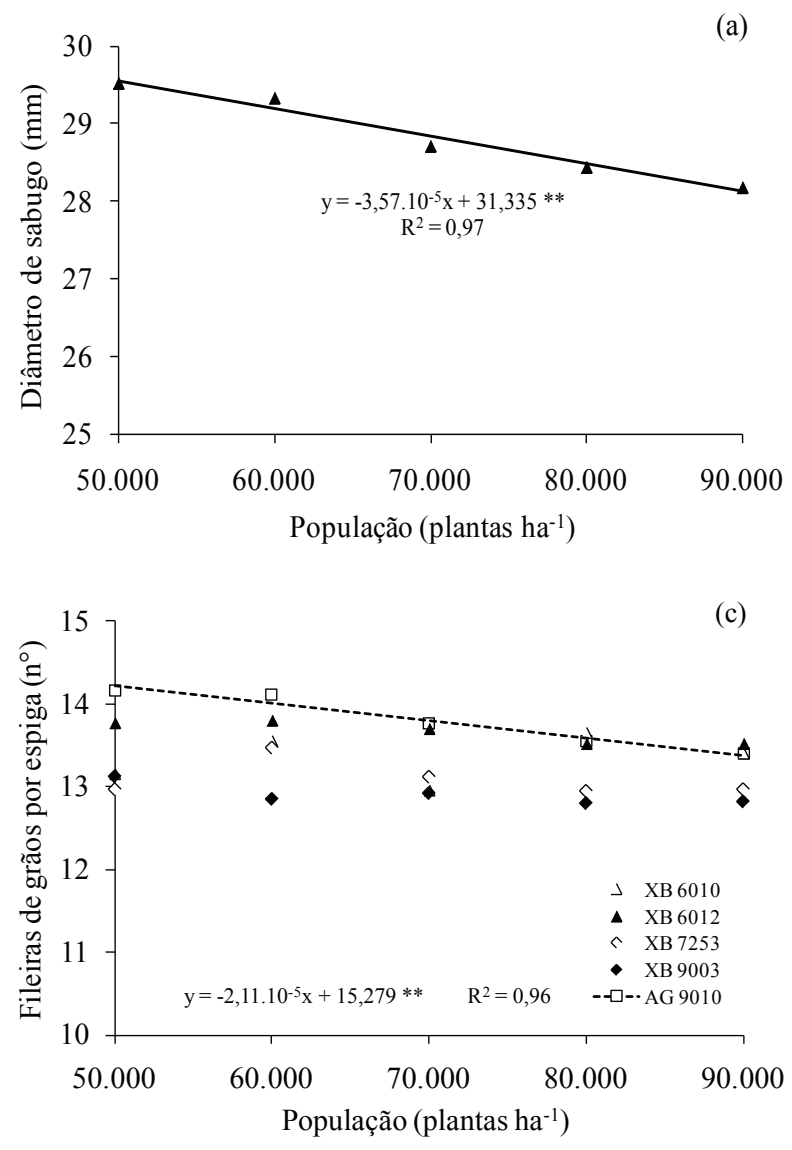

$\mathrm{Na}$ análise de regressão, apenas os dados dos híbridos XB 7253, XB 9003 e AG 9010 tiveram ajustes de equações significativos para o comprimento de grão (Figura 3b). O modelo quadrático foi o que melhor se ajustou às médias dos híbridos XB 7253 e XB 9003. O comprimento máximo de grão estimado foi de $10,0 \mathrm{~mm}$, com a população de 65.789 plantas ha ${ }^{-1}$, para o híbrido XB 7253, enquanto o XB 9003 não obteve ponto de máxima estimado pela equação quadrática. O comprimento de grão do híbrido AG 9010 diminuiu linearmente à medida que se elevou a população de plantas, concordando com os resultados obtidos por Brachtvogel et al. (2009). Desta forma, infere-se que a resposta linear do diâmetro de sabugo ao incremento da população (Figura 3a) favoreceu o aparecimento de uma mesma tendência no comprimento de grão, uma vez que este foi obtido pela diferença entre diâmetro de espiga e de sabugo, conforme mencionado anteriormente.

O número de fileiras de grãos por espiga não foi afetado pela alteração no espaçamento, mas
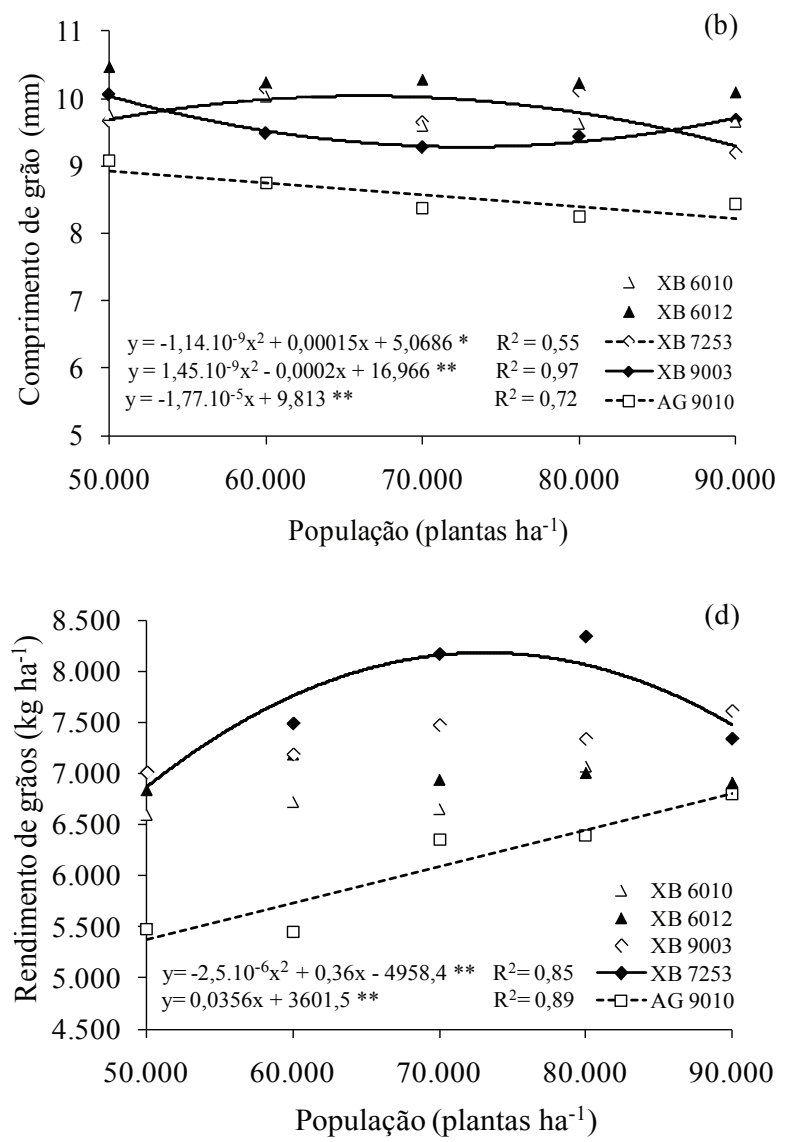

Figura 3. Diâmetro de sabugo (a), comprimento de grão (b), número de fileiras de grãos por espiga (c) e rendimento de grãos de milho (d), em função de populações de plantas (Selvíria, MS, 2009). ** e * Significativo a 1\% e 5\%, respectivamente, pelo teste F. 
pelo efeito independente de híbrido, população de plantas e interação entre estes fatores (Tabela 1). Diferentemente do observado neste estudo, Palhares (2003) obteve aumento do número de fileiras de grãos por espiga do genótipo DKB 911, pela redução de $0,80 \mathrm{~m}$ para $0,40 \mathrm{~m}$ entre linhas, sob a população de 30.000 plantas ha ${ }^{-1}$. No desdobramento da interação entre híbrido e população de plantas (Tabela 4), os híbridos XB 6010, XB 6012, XB 7253 e AG 9010 tiveram comportamento similar, quando submetidos às populações de 60.000 plantas ha $^{-1}, 70.000$ plantas ha $^{-1}$ e 80.000 plantas ha $^{-1}$, apresentando maior número de fileiras de grãos por espiga. Na presença de 50.000 plantas $\mathrm{ha}^{-1}$, maior número de fileiras foi verificado nos híbridos AG 9010 e XB 6012, ao passo que, para 90.000 plantas ha-1 $^{-1}$, não houve diferença entre os genótipos.

$\mathrm{Na}$ análise de regressão, apenas o híbrido AG 9010 teve ajuste significativo de equação (Figura 3c). Nota-se que o incremento na população provocou redução linear do número de fileiras de grãos por espiga. A alta população ( 90.000 plantas ha $\left.^{-1}\right)$ propiciou a intensificação da competição intraespecífica por luz, no referido genótipo, fato que pode explicar o menor número de fileiras de grãos por espiga, observado nesta condição. Os dados obtidos corroboram os de Brachtvogel (2008) e Furtado (2005), os quais observaram que, à medida que se elevou a população, o número de fileiras de grãos diminuiu. Entretanto,
Marchão et al. (2005) obtiveram resultados diferentes, pois chegaram à conclusão de que o número de fileiras de grãos por espiga não foi influenciado pelo aumento na densidade populacional. Os referidos autores relacionaram tal resultado ao fato de o potencial de produção ser definido no primeiro estádio de desenvolvimento, quando ocorre o início do processo de diferenciação floral e a formação dos primórdios da espiga, não havendo, ainda, uma influência significativa da competição por plantas, no ambiente.

O rendimento de grãos apresentou comportamento distinto, em razão da interação entre híbrido e espaçamento e entre híbrido e população (Tabela 1), corroborando os resultados de Penariol et al. (2003). Cruz et al. (2007) constataram que o rendimento foi afetado pela interação entre espaçamento e densidades de semeadura, em dois anos agrícolas, fato que, neste estudo, não foi constatado.

A redução do espaçamento de $0,90 \mathrm{~m}$ para 0,45 m entre linhas não foi eficiente no aumento do rendimento de grãos dos híbridos XB 6010, XB 6012, XB 7253 e XB 9003 (Tabela 5). Contudo, o híbrido AG 9010 apresentou maior rendimento de grãos no espaçamento de $0,45 \mathrm{~m}$, indicando, claramente, que, para este genótipo de arquitetura diferenciada, a redução do espaçamento foi vantajosa. A superioridade constatada foi de $15 \%$ a favor do espaçamento reduzido, semelhante ao resultado de ensaios obtidos nas regiões Sul, Sudeste e Centro-Oeste do Brasil,

Tabela 3. Desdobramento da interação entre híbrido e população de plantas, para comprimento de grão (mm), na cultura do milho (Selvíria, MS, 2009).

\begin{tabular}{|c|c|c|c|c|c|}
\hline \multirow{2}{*}{ Híbrido } & \multicolumn{5}{|c|}{ Comprimento de grão $(\mathrm{mm})$} \\
\hline & 50.000 plantas ha-1 & 60.000 plantas ha ${ }^{-1}$ & 70.000 plantas ha-1 & 80.000 plantas ha-1 & 90.000 plantas ha $^{-1}$ \\
\hline XB 6010 & $9,8 \mathrm{ab}$ & $10,0 \mathrm{a}$ & $9,6 \mathrm{ab}$ & $9,6 \mathrm{a}$ & $9,7 \mathrm{a}$ \\
\hline XB 6012 & $10,5 \mathrm{a}$ & $10,2 \mathrm{a}$ & $10,3 \mathrm{a}$ & $10,2 \mathrm{a}$ & $10,1 \mathrm{a}$ \\
\hline XB 7253 & $9,7 \mathrm{ab}$ & $10,1 \mathrm{a}$ & $9,6 \mathrm{ab}$ & $10,1 \mathrm{a}$ & $9,2 \mathrm{ab}$ \\
\hline XB 9003 & $10,1 \mathrm{a}$ & $9,5 \mathrm{ab}$ & $9,3 \mathrm{bc}$ & $9,4 \mathrm{a}$ & $9,7 \mathrm{a}$ \\
\hline AG 9010 & $9,1 \mathrm{~b}$ & $8,7 \mathrm{~b}$ & $8,4 \mathrm{c}$ & $8,2 \mathrm{~b}$ & $8,4 \mathrm{~b}$ \\
\hline
\end{tabular}

Médias seguidas por mesma letra, nas colunas, não diferem pelo teste Tukey (5\%).

Tabela 4. Desdobramento da interação entre híbrido e população de plantas, para número de fileiras de grãos por espiga, na cultura do milho (Selvíria, MS, 2009).

\begin{tabular}{|c|c|c|c|c|c|}
\hline \multirow{2}{*}{ Híbrido } & \multicolumn{5}{|c|}{ Número de fileiras de grãos por espiga } \\
\hline & 50.000 plantas ha ${ }^{-1}$ & 60.000 plantas ha-1 & 70.000 plantas ha ${ }^{-1}$ & 80.000 plantas ha ${ }^{-1}$ & 90.000 plantas ha $^{-1}$ \\
\hline XB 6010 & $13,1 \mathrm{~b}$ & $13,5 \mathrm{ab}$ & $12,9 \mathrm{ab}$ & $13,6 \mathrm{a}$ & $13,4 \mathrm{a}$ \\
\hline XB 6012 & $13,8 \mathrm{ab}$ & $13,8 \mathrm{a}$ & $13,7 \mathrm{ab}$ & $13,5 \mathrm{ab}$ & $13,5 \mathrm{a}$ \\
\hline XB 7253 & $12,9 \mathrm{~b}$ & $13,5 \mathrm{ab}$ & $13,1 \mathrm{ab}$ & $12,9 \mathrm{ab}$ & $12,9 \mathrm{a}$ \\
\hline XB 9003 & $13,2 \mathrm{~b}$ & $12,8 \mathrm{~b}$ & $12,9 \mathrm{~b}$ & $12,8 \mathrm{~b}$ & $12,8 \mathrm{a}$ \\
\hline AG 9010 & $14,2 \mathrm{a}$ & $14,1 \mathrm{a}$ & $13,8 \mathrm{a}$ & $13,5 \mathrm{ab}$ & $13,4 \mathrm{a}$ \\
\hline
\end{tabular}

Médias seguidas por mesma letra, nas colunas, não diferem pelo teste Tukey (5\%). 
em que os ganhos de rendimento de grãos foram de até $14 \%$, com a adoção desta prática. No tocante ao comportamento de híbridos dentro de espaçamento, os híbridos XB 7253 e XB 9003 apresentaram maior rendimento sob $0,45 \mathrm{~m}$ entre linhas. A superioridade produtiva dos referidos genótipos foi mantida no espaçamento de $0,90 \mathrm{~m}$, juntamente com o XB 6012.

$\mathrm{O}$ aumento do rendimento de grãos, com a redução do espaçamento, é atribuído à maior eficiência na interceptação de radiação e ao decréscimo de competição por luz, água e nutrientes, entre as plantas na linha, devido à sua distribuição mais equidistante (Argenta et al. 2001b). Dourado Neto et al. (2003) e Penariol et al. (2003) obtiveram ganhos em rendimento de grãos com uso de espaçamento reduzido, na cultura do milho. Em contrapartida, Flesch \& Viera (2004) não detectaram diferença significativa para redução do espaçamento no rendimento de grãos de diferentes híbridos de milho. No entanto, verificaram que esta prática mostrou-se efetiva no controle de plantas daninhas.

No comportamento de híbridos, em função da variação na população de plantas (Tabela 6), nota-se que os genótipos XB 6010, XB 6012, XB 7253 e XB 9003 apresentaram maiores rendimentos de grãos sob 50.000 plantas ha $^{-1}$ e 60.000 plantas ha ${ }^{-1}$. Em condições de 70.000 plantas ha $^{-1}$ e 80.000 plantas ha $^{-1}$, a superioridade produtiva foi constatada apenas nos híbridos XB 7253 e XB 9003. Na população de 90.000 plantas ha $^{-1}$, não houve diferença significativa entre os híbridos.
Apenas os híbridos XB 7253 e AG 9010 tiveram ajustes de equações significativos pela análise de regressão (Figura 3d). Os coeficientes de determinação $\left(\mathrm{R}^{2}\right)$ de $85 \%$ e $89 \%$ indicam que a maioria da variação observada foi explicada pela regressão quadrática e linear, respectivamente. O híbrido XB 7253 respondeu, de forma quadrática, ao aumento da população de plantas, incrementando o rendimento de grãos a partir de 50.000 plantas ha $^{-1}$ até 70.000 plantas $\mathrm{ha}^{-1} \mathrm{e}$ diminuindo a 90.000 plantas $^{-1} \mathrm{a}^{-1}$, semelhantemente ao constatado por Flesch \& Vieira (2004) e Sangoi et al. (2007). Pela equação da curva de resposta, foi estimado o rendimento máximo em $8.000 \mathrm{~kg} \mathrm{ha}^{-1}$, com a utilização da população de máxima eficiência técnica de 72.000 plantas ha-1 $^{-1}$, qual se caracteriza como a população ideal para a combinação genótipo-ambiente.

Com certa semelhança ao evidenciado no presente estudo, Marchão et al. (2005) constataram que a maioria dos híbridos avaliados alcançaram maiores rendimentos com populações acima de 70.000 plantas ha-1, com exceção dos genótipos A 2288 e AG 6690. Estudos recentes também têm mostrado respostas positivas de rendimento de grãos do milho, pelo incremento da população, com rendimentos atingindo ponto máximo entre 70.000 plantas ha $^{-1}$ e 80.000 plantas ha $^{-1}$ e declinando em populações mais altas (Dourado Neto et al. 2003, Penariol et al. 2003, Alvarez et al. 2006, Gross et al. 2006). Isto demonstra que, em ambientes favoráveis, o ambiente e o potencial dos genótipos atuais de milho podem estar sendo subutilizados.

Tabela 5. Desdobramento da interação entre híbrido e espaçamento, para rendimento de grãos ( $\left.\mathrm{kg} \mathrm{ha}^{-1}\right)$, na cultura do milho (Selvíria, MS, 2009).

\begin{tabular}{cccccc}
\hline \multirow{2}{*}{ Espaçamento } & \multicolumn{5}{c}{ Rendimento de grãos $\left(\mathrm{kg} \mathrm{ha}^{-1}\right)$} \\
\cline { 2 - 5 } & $\mathrm{XB} \mathrm{6010}$ & XB 6012 & XB 7253 & XB 9003 & AG 9010 \\
\hline $0,45 \mathrm{~m}$ & $6.835 \mathrm{aC}$ & $6.914 \mathrm{aBC}$ & $7.776 \mathrm{aA}$ & $7.496 \mathrm{aAB}$ & $6.582 \mathrm{aC}$ \\
$0,90 \mathrm{~m}$ & $6.740 \mathrm{aB}$ & $7.033 \mathrm{aAB}$ & $7.551 \mathrm{aA}$ & $7.142 \mathrm{aAB}$ & $5.605 \mathrm{bC}$ \\
\hline
\end{tabular}

Médias seguidas por mesma letra minúscula, nas colunas, e por mesma letra maiúscula, nas linhas, não diferem pelo teste Tukey (5\%).

Tabela 6. Desdobramento da interação entre híbrido e população de plantas, para rendimento de grãos $\left(\mathrm{kg} \mathrm{ha}^{-1}\right)$, na cultura do milho (Selvíria, MS, 2009).

\begin{tabular}{|c|c|c|c|c|c|}
\hline \multirow{2}{*}{ Híbrido } & \multicolumn{5}{|c|}{ Rendimento de grãos $\left(\mathrm{kg} \mathrm{ha}^{-1}\right)$} \\
\hline & 50.000 plantas ha $^{-1}$ & 60.000 plantas ha $^{-1}$ & 70.000 plantas ha $^{-1}$ & 80.000 plantas ha $^{-1}$ & 90.000 plantas ha-1 \\
\hline XB 6010 & $6.591 \mathrm{ab}$ & $6.719 \mathrm{a}$ & $6.648 \mathrm{bc}$ & $7.070 \mathrm{~b}$ & $6.910 \mathrm{a}$ \\
\hline XB 6012 & $6.837 \mathrm{a}$ & $7.182 \mathrm{a}$ & $6.937 \mathrm{bc}$ & $7.003 \mathrm{~b}$ & $6.909 \mathrm{a}$ \\
\hline XB 7253 & $7.008 \mathrm{a}$ & $7.484 \mathrm{a}$ & $8.160 \mathrm{a}$ & $8.330 \mathrm{a}$ & $7.336 \mathrm{a}$ \\
\hline XB 9003 & $7.006 \mathrm{a}$ & $7.181 \mathrm{a}$ & $7.468 \mathrm{ab}$ & $7.333 \mathrm{ab}$ & $7.606 \mathrm{a}$ \\
\hline AG 9010 & $5.480 \mathrm{~b}$ & $5.455 \mathrm{~b}$ & $6.351 \mathrm{c}$ & $6.390 \mathrm{~b}$ & $6.792 \mathrm{a}$ \\
\hline
\end{tabular}

Médias seguidas por mesma letra, nas colunas, não diferem pelo teste Tukey (5\%). 
O rendimento de grãos do AG 9010 aumentou linearmente, com o incremento na população de plantas (Figura 3d), podendo-se inferir que, para cada aumento de 1.000 plantas ha $^{-1}$, ocorreu acréscimo de $35,6 \mathrm{~kg} \mathrm{ha}^{-1}$ em seu rendimento, no intervalo de populações considerado. Marchão et al. (2005) também verificaram resposta linear no rendimento de grãos do híbrido AG 9010, com incremento da população, nos dois experimentos que conduziram. Cruz et al. (2007) verificaram que o rendimento de grãos foi afetado pela interação entre espaçamento e população de plantas, sendo que o rendimento cresceu linearmente com o aumento de 40.000 plantas ha $^{-1}$ para 77.500 plantas $^{-1} \mathrm{a}^{-1}$, em ambos os espaçamentos testados $(0,50 \mathrm{~m}$ e $0,80 \mathrm{~m}$ entre linhas $)$. Nota-se que, para híbridos com folhas eretas e menor altura de planta, a população ideal tende a ser maior. No entanto, esta população ideal, para cada híbrido, também pode ser menor, se a lavoura for submetida a algum estresse ambiental.

A resposta linear, em rendimento de grãos, do AG 9010 pode ser atribuída à melhor ocupação da área e melhor aproveitamento dos recursos disponíveis, favorecida pela sua arquitetura diferenciada, em comparação aos demais genótipos mensurados. Isto é um indicativo de que o referido genótipo foi o mais exigente em população de plantas, para maximizar o rendimento de grãos, e que, dependendo do híbrido a ser utilizado, o incremento na população de plantas pode ser uma prática de manejo que permite aumento no rendimento. Como a regressão não mostrou ponto de máxima, fica a indicação de que, nas condições estudadas, a população do AG 9010 pode ser aumentada além de 90.000 plantas ha-1.

O aumento da população de plantas do híbrido AG 9010 permite a colheita de um maior número de espigas por unidade de área. A diminuição do tamanho das espigas, com o incremento na população, é suplantada pelo aumento do número das mesmas, neste caso. Este fato leva a acreditar, ainda, que a utilização de híbridos de milho de baixo porte, como o AG 9010, associada à utilização de espaçamento reduzido, deve ser acompanhada de incrementos na população de plantas, especialmente em lavouras de alto nível tecnológico e em regiões com características climáticas favoráveis, desde que se usem híbridos tolerantes ao acamamento.

Penariol et al. (2003) constataram comportamento distinto entre dois genótipos de milho, quando submetidos a diferentes densidades de semeadura. Os referidos autores evidenciaram que o híbrido AG 9010 apresentou aumento linear de rendimento de grãos, com o aumento da densidade de plantas, enquanto a variedade BR 473 mostrou resposta quadrática, em relação ao aumento populacional, com ponto máximo de rendimento alcançando população de 71.000 plantas ha-1 $^{-1}$. Resende et al. (2003), trabalhando com espaçamentos ( $0,45 \mathrm{~m} ; 0,70 \mathrm{~m}$; e $0,90 \mathrm{~m}$ entre linhas) e populações (55.000 plantas ha $\mathrm{ha}^{-1}, 70.000$ plantas $\mathrm{ha}^{-1} \mathrm{e}$ 90.000 plantas ha $^{-1}$ ), também constataram aumento linear no rendimento de grãos, com o aumento na população, independentemente dos genótipos avaliados. Aumentos no rendimento de grãos, com o incremento na população de plantas, também foram constatados no trabalho de Silva et al. (2008).

De maneira geral, a redução do espaçamento não afetou a maioria dos caracteres mensurados neste estudo, o que também foi observado por Argenta et al. (2001a), Flesch \& Vieira (2004), Penariol et al. (2003) e Scheeren et al. (2004). No estudo de Kunz (2005), o único componente de produção influenciado pelo espaçamento foi a massa de grãos por espiga, a qual foi maior no espaçamento de $0,90 \mathrm{~m}$, em relação ao de $0,45 \mathrm{~m}$.

Com relação à população, esta influenciou todos os caracteres, confirmando relatos na literatura, em que as características de perfilhamento pobre e ausência de ramificação fazem da planta de milho a poácea mais sensível à variação da densidade de semeadura. Em comparação com a manipulação do espaçamento, a densidade populacional é a que tem maior efeito no rendimento de grãos do milho, já que pequenas alterações na população implicam em modificações relativamente grandes no rendimento final da cultura (Silva et al. 2006).

\section{CONCLUSÕES}

1. A alteração no espaçamento entre linhas influenciou apenas o rendimento de grãos do híbrido AG 9010, sendo que a utilização do espaçamento reduzido $(0,45 \mathrm{~m})$ apresentou-se como vantajosa, ao incrementar o rendimento em $15 \%$, em relação ao espaçamento de $0,90 \mathrm{~m}$ entre linhas.

2. O incremento na população de plantas influenciou negativamente a maioria das características mensuradas.

3. Os melhores arranjos foram AG $9010(90.000$ plantas $\left.\mathrm{ha}^{-1}\right)$, no espaçamento de $0,45 \mathrm{~m}$ entre linhas; XB 7253 (70.000 plantas ha-1), nos dois 
espaçamentos; e XB 6010, XB 6012 e XB 9003, sem resposta significativa aos arranjos espaciais, podendo ser recomendado o de 50.000 plantas ha- $^{-1}$, em ambos os espaçamentos.

\section{AGRADECIMENTOS}

\author{
À Coordenação de Aperfeiçoamento de Pessoal de \\ Ensino Superior (CAPES), pela bolsa de estudo \\ concedida ao primeiro autor.
}

\section{REFERÊNCIAS}

ALVAREZ, C. G. D.; VON PINHO, R. G.; BORGES, I. D. Avaliação de características agronômicas e de produção de forragem e grãos de milho em diferentes densidades de semeadura e espaçamentos entre linhas. Ciência e Agrotecnologia, Lavras, v. 30, n. 3, p. 402-408, 2006.

ARGENTA, G. et al. Resposta de híbridos simples de milho à redução do espaçamento entre linhas. Pesquisa Agropecuária Brasileira, Brasília, DF, v. 36, n. 1, p. 7178, 2001a.

ARGENTA, G.; SILVA, P. R. F.; SANGOI, L. Arranjo de plantas em milho: análise do estado-da-arte. Ciência Rural, Santa Maria, v. 31, n. 6, p. 1075-1084, 2001 b.

BRACHTVOGEL, E. L. Densidades e arranjos populacionais de milho e componentes agronômicos. 2008. 96 f. Dissertação (Mestrado em Agronomia)-Faculdade de Ciências Agronômicas, Universidade Estadual Paulista, Botucatu, 2008.

BRACHTVOGEL, E. L. et al. Densidades populacionais de milho em arranjos espaciais convencional e equidistante entre plantas. Ciência Rural, Santa Maria, v. 39, n. 8, p. 2334-2339, 2009.

BRUNS, H. A.; ABBAS, H. K. Ultra-high plant populations and nitrogen fertility effects on corn in the Mississippi Valley. Agronomy Journal, Madison, v. 97, n. 4, p. 1136-1140, 2005.

CARDOSO, M. J. et al. Desempenho de híbridos de milho na região meio-norte do Brasil. Revista Brasileira de Milho e Sorgo, Sete Lagoas, v. 2, n. 1, p. 43-52, 2003.

CARVALHO, I. Q. Espaçamento entre fileiras e população de plantas em milho. 2007. 118 f. Dissertação (Mestrado em Agronomia)-Universidade Estadual de Ponta Grossa, Ponta Grossa, 2007.

CENTURION, J. F. Balanço hídrico da região de Ilha Solteira. Cientifica, Jaboticabal, v. 10, n. 1, p. 57-61, 1982.
COSTA, A. C. S. et al. Perdas de nitrogênio por volatilização da amônia em três solos argilosos tratados com ureia. Acta Scientiarum Agronomy, Maringá, v. 26, n. 4, p. 467-473, 2004.

CRUZ, J. C. et al. Resposta de cultivares de milho à variação em espaçamento e densidade. Revista Brasileira de Milho e Sorgo, Sete Lagoas, v. 6, n. 1, p. 60-73, 2007.

DEMÉTRIO, C. S. Desempenho agronômico de híbridos de milho em diferentes arranjos populacionais em Jaboticabal - SP. 2008. 53 f. Dissertação (Mestrado em Produção Vegetal)-Faculdade de Ciências Agrárias e Veterinárias, Universidade Estadual Paulista, Jaboticabal, 2008.

DIDONET, A. D. et al. Efeito da radiação solar e temperatura na definição do número de grãos de milho. Pesquisa Agropecuária Brasileira, Brasília, DF, v. 37, n. 7, p. 933-938, 2002.

DOURADO NETO, D. et al. Efeito da população de plantas e do espaçamento sobre a produtividade de milho. Revista Brasileira de Milho e Sorgo, Sete Lagoas, v. 2, n. 3, p. 63-77, 2003.

EMPRESA BRASILEIRA DE PESQUISA AGROPECUÁRIA (Embrapa). Centro Nacional de Pesquisa de Solos. Sistema brasileiro de classificação de solos. 2. ed. Brasília, DF: Embrapa-SPI; Rio de Janeiro: Embrapa Solos, 2006.

FANCELLI, A. L.; DOURADO NETO, D. Produção de milho. 2. ed. Guaíba: Agropecuária, 2004.

FLESCH, R. D.; VIEIRA, L. C. Espaçamentos e densidades de milho com diferentes ciclos no oeste de Santa Catarina, Brasil. Ciência Rural, Santa Maria, v. 34, n. 1, p. 25-31, 2004.

FURTADO, M. B. Sistemas de preparo do solo e populações de plantas em espaçamento reduzido: comportamento de cultivares de milho (Zea mays L.). 2005. 87 f. Dissertação (Mestrado em Agronomia/Agricultura)-Faculdade de Ciências Agronômicas, Universidade Estadual Paulista "Júlio de Mesquita Filho", Botucatu, 2005.

GOMES, F. P.; GARCIA, C. H. Estatística aplicada a experimentos agronômicos e florestais: exposição com exemplos e orientações para uso de aplicativos. Piracicaba: Fealq, 2002.

GROSS, M. R.; VON PINHO, R. G.; BRITO, A. H. Adubação nitrogenada, densidade de semeadura e espaçamento entre fileiras na cultura do milho em sistema plantio direto. Ciência e Agrotecnologia, Lavras, v. 30, n. 3, p. 387-393, 2006.

KAPPES, C. et al. Influência do nitrogênio no desempenho produtivo do milho cultivado na segunda safra em sucessão à soja. Pesquisa Agropecuária Tropical, Goiânia, v. 39, n. 3, p. 251-259, 2009. 
KUNZ, R. P. Influência do arranjo de plantas e da população em características agronômicas e produtividade do milho. 2005. 115 f. Dissertação (Mestrado em Produção Vegetal)-Universidade Estadual de Ponta Grossa, Ponta Grossa, 2005.

MARCHÃO, R. L. et al. Densidade de plantas e características agronômicas de híbridos de milho sob espaçamento reduzido entre linhas. Pesquisa Agropecuária Tropical, Goiânia, v. 35, n. 2, p. 93-101, 2005.

PALHARES, M. Distribuição e população de plantas e produtividade de grãos de milho. 2003. 90 f. Dissertação (Mestrado em Fitotecnia)-Escola Superior de Agricultura "Luiz de Queiroz", Universidade de São Paulo, Piracicaba, 2003.

PENARIOL, F. G. et al. Comportamento de cultivares de milho semeadas em diferentes espaçamentos entre linhas e densidades populacionais, na safrinha. Revista Brasileira de Milho e Sorgo, Sete Lagoas, v. 2, n. 2, p. 52-60, 2003.

RAIJ, B. Van et al. Recomendações de adubação e calagem para o Estado de São Paulo. 2. ed. Campinas: Instituto Agronômico, 1996. (Boletim técnico, 100).

RESENDE, S. G.; VON PINHO, R. G.; VASCONCELOS, R. C. Influência do espaçamento entre linhas e da densidade de plantio no desempenho de cultivares de milho. Revista Brasileira de Milho e Sorgo, Sete Lagoas, v. 2, n. 3, p. 34-42, 2003.
SANGOI, L. et al. Desempenho agronômico de cultivares de milho em quatro sistemas de manejo. Revista Brasileira de Milho e Sorgo, Sete Lagoas, v. 5, n. 2, p. 218-231, 2006.

SANGOI, L. et al. Sustentabilidade do colmo em híbridos de milho de diferentes épocas de cultivo em função da densidade de plantas. Revista de Ciências Agroveterinárias, Lages, v. 1, n. 2, p. 60-66, 2002.

SANGOI, L.; SCHMITT, A.; ZANIN, C. G. Área foliar e rendimento de grãos de híbridos de milho em diferentes populações de plantas. Revista Brasileira de Milho e Sorgo, Sete Lagoas, v. 6, n. 3, p. 263-271, 2007.

SCHEEREN, B. R. et al. Arranjo populacional para a cultura do milho na região central do Estado de Mato Grosso do Sul. Acta Scientiarum Agronomy, Maringá, v. 26, n. 2, p. 55-60, 2004.

SILVA, A. G. et al. Influência da população de plantas e do espaçamento entre linhas nos caracteres agronômicos do híbrido de milho P30K75 em Rio Verde, Goiás. Bioscience Journal, Uberlândia, v. 24, n. 2, p. 89-96, 2008.

SILVA, P. R. F. et al. Arranjo de plantas e sua importância na definição da produtividade em milho. Porto Alegre: Evangraf, 2006.

TOLLENAAR, M. Is low plant density a stress in maize? Maydica, Bergamo, v. 37, n. 2, p. 305-311, 1992. 